\title{
Household food insufficiency is associated with dietary intake in Korean adults
}

\author{
Sang Eun Lee ${ }^{1}$, Yoon Ju Song ${ }^{2}$, Young Kim ${ }^{3}$, Jeongsook $\mathrm{Choe}^{3}$ and Hee-Young Paik ${ }^{1, *}$ \\ 'Department of Food and Nutrition, Seoul National University, 1 Gwanak-ro, Gwanak-gu, Seoul 151-742, Republic \\ of Korea: ${ }^{2}$ Major of Food and Nutrition, School of Human Ecology, The Catholic University of Korea, Bucheon, \\ Republic of Korea: ${ }^{3}$ National Academy of Agricultural Science, Rural Development Administration, Jeonju, \\ Republic of Korea
}

Submitted 22 August 2014: Final revision received 6 June 2015: Accepted 14 July 2015: First published online 24 August 2015

\begin{abstract}
Objective: To examine the association of food insufficiency with dietary intake and eating and health behaviours.

Design: A cross-sectional study.

Setting: Data were obtained from a secondary source, the Fifth Korea National Health and Nutrition Examination Survey (2010-2012).

Subjects: The sample size consisted of 15603 adults over 19 years of age (8898 households).

Results: Significant differences in socio-economic factors were observed according to food insufficiency level $(P<0.05)$, but BMI was similar among groups. Regarding macronutrients, lower protein intake and higher carbohydrate intake were found in the severely food-insufficient group, but we found no association with fat intake. Regarding micronutrients, Ca, Fe, vitamin A, thiamin, riboflavin niacin and vitamin $\mathrm{C}$ intakes were negatively associated with food insufficiency level $\left(P_{\text {trend }}<0 \cdot 05\right)$. Consumption of different food groups, such as meat, fish, eggs and beans, vegetables and fruits, was significantly lower as food insufficiency level decreased after controlling for all possible variables; food group consumption also differed by sex. Overall eating and health behaviours were poorer in the mildly and severely food-insufficient groups, who received more food assistance but less nutritional education.

Conclusions: Our results showed that dietary intake as well as eating and health behaviours are adversely associated with food insufficiency. These findings suggest that specific strategies to help food-insufficient individuals should be developed in order to improve their dietary quality and health status.
\end{abstract}

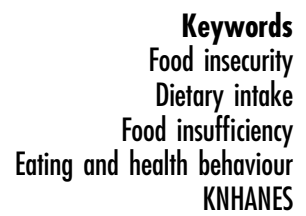

KNHANES
Food insecurity has become a growing concern over the past decade. Often referred to as hunger, food poverty or food insufficiency in earlier studies ${ }^{(1-3)}$, food insufficiency status was used as one of the indicators to measure food insecurity $^{(2)}$. Food insecurity, which means that the access to adequate food is limited by lack of money and other resources during the year ${ }^{(4)}$, has multiple dimensions and a more comprehensive meaning than food insufficiency since the concept of food insecurity includes quantity, quality, feelings of deprivation and disrupted eating ${ }^{(5)}$. Thus, food insecurity has been an important issue in Western industrialised countries, as well as in developing countries suffering from food shortages and hunger. Numerous studies ${ }^{(1-3,5-17)}$ of food insecurity have been performed in Western countries. Those studies have found that food insecurity is associated with poor dietary quality and less-healthy food consumption behaviours $(6,9,11,12,14)$. A recent review article ${ }^{(5)}$ indicated that food insecurity was consistently associated with poorer dietary quality in the US adult population, with food-insecure adults consuming fewer vegetables, fruits and dairy products than foodsecure adults. Several studies ${ }^{(2,7)}$ also have reported that food insecurity is associated with poorer health or chronic disease. A study ${ }^{(2)}$ using Canadian national data reported that individuals in food-insufficient households had significantly higher odds of having a poor general health status and selected chronic conditions, such as heart disease and diabetes. In the USA, food insecurity was significantly associated with self-reported hypertension and hyperlipidaemia among low-income participants in the National Health and Nutrition Examination Survey $(\text { NHANES })^{(7)}$. 
Food insecurity has received considerable attention in South Korea, a country that ranked thirteenth in gross domestic product in the world in $2014^{(18)}$ and that is one of the OECD (Organisation for Economic Co-operation and Development) countries. The typical Korean diet is unique and differs widely from a Western diet, consisting of steamed rice, soup, and several side dishes that usually include one main dish containing meat or fish and others that include a variety of vegetables, along with Korean fermented cabbage (kimchi). Thus, the Korean diet is regarded as a high-carbohydrate low-fat diet with ample plant foods.

Compared with Western nations, however, studies related to food insecurity and dietary quality in Asia, including South Korea, are scarce. In Taiwan, a study of 240 households reported that low-income families had more frequent food security worries and consumed significantly fewer dairy products, fruits and fish in daily meals than middle-income families ${ }^{(19)}$; a study of 1783 elderly people using dietary diversity and food expenditure as surrogates for food insecurity reported that higher total food expenditure was associated with a higher dietary diversity score, even after controlling for household income ${ }^{(20)}$. In South Korea, a study of 370 children reported that household food insecurity was associated with more frequent intakes of cheap and low-quality foods and higher weight status among low-income urban families ${ }^{(21)}$; however, that study used a small sample.

Thus, in the present study, we used nationally representative survey data to examine the association between food insecurity and dietary quality in the Korean adult population (19 years of age or older). We also compared eating and health behaviours according to the level of household food insecurity.

\section{Methods}

\section{Data source and study participants}

Data were obtained from the Fifth Korea National Health and Nutrition Examination Survey (KNHANES; 2010-2012) ${ }^{(22)}$, a nationally representative, stratified, multistage sampling and cross-sectional survey that consists of three parts: a health interview survey, a health examination survey and a nutrition survey. The health interview and health examination surveys were performed at mobile examination centres that travel to survey areas, and the nutrition survey, including a one-day $24 \mathrm{~h}$ recall for each respondent, was administered in respondents' homes by trained interviewers $^{(23)}$. The sample population for KNHANES was non-institutionalised South Korean civilians aged 1 year or older ${ }^{(22,23)}$. KNHANES is conducted by the Korea Centers for Disease Control and Prevention (Korea CDC) and is approved by the Institutional Review Board of the Korea CDC (IRB numbers 2010-02CON-21-C, 2011-02CON-06-C and 2012-01EXP-01-2C). For KNHANES
2010-2012, 576 sampling units (192 per year) were randomly selected from the primary sampling units based on a sampling framework of all census blocks or resident registration addresses in South $\mathrm{Korea}^{(22,23)}$. Twenty households per primary sampling unit were selected. A total of 9821 households and 25534 household members completed the survey. All of the participants provided written informed consent. In the present study, eligible individuals included 19599 adults 19 years of age and older. Individuals were excluded if sociodemographic ( $n$ 1791) or anthropometric data ( $n$ 1082) were missing, or if the individual did not participate in the $24 \mathrm{~h}$ recall ( $n$ 2205). In total, the study included data of 15603 adults from 8898 households.

\section{Food insufficiency measurement}

Food insufficiency was determined as a part of the household questionnaire, which included a question regarding food insufficiency for the current year as translated into Korean from the NHANES III 'food sufficiency questions' established by the US Department of Agriculture $^{(1,8,9)}$ : 'Which of the following statements best describes the food eaten in your household?' Potential answers included: 'Enough of the kinds of food we want to eat' (\#1); 'Enough but not always the kinds of food we want' (\#2); 'Sometimes not enough to eat' (\#3); and 'Often not enough to eat' (\#4). Four criteria were merged into three, and we divided participants into three groups: (i) a food-sufficient group who responded with answer \#1 (i.e. enough of the kinds of food we want to eat); (ii) a mildly food-insufficient group who responded with answer \#2 (i.e. enough but not always the kinds of food we want); and (iii) a severely food-insufficient group who responded with answer \#3 (i.e. sometimes not enough to eat) or \#4 (i.e. often not enough to eat). The sensitivity and specificity of the food insufficiency questionnaire with a single item were reported as $56.8 \%$ and $92.3 \%$, respectively ${ }^{(24)}$.

\section{Dietary assessment}

Dietary intake information was obtained from KNHANES $24 \mathrm{~h}$ recall data. Nutrient intakes and food group consumption were compared among the food insufficiency status groups. Total energy intake was compared among groups and was also evaluated as a percentage of the estimated energy requirement (EER). Each individual's EER was calculated based on the formula and method used for the Dietary Reference Intakes for Koreans ${ }^{(25)}$, assuming that all individuals participated in a low level of physical activity. The method was based on a review that estimated the physical activity coefficient from studies published since 2005. It showed that most South Koreans' physical activity level was 1.40-1.59, which is the low active level ${ }^{(25)}$. \%EER is the percentage of total energy intake per day relative to the EER, calculated per person.

To evaluate food intake, the recommended servings of six major food groups were used. The six food groups 
and their respective daily recommended servings are presented in the 2010 Korean Food Guidance System as a part of the Dietary Reference Intakes for Koreans ${ }^{(25)}$. The intake for the six food groups was calculated as a percentage of the recommended daily serving consumed (\%RS) based on the number of servings. The six food groups were: (i) grains; (ii) meat, fish, eggs and beans (MFEB); (iii) vegetables; (iv) fruits; (v) milk and dairy products; and (vi) oils and sugars. The calculation of food group consumption by the recommended serving is described in detail elsewhere ${ }^{(26)}$. Briefly, common serving sizes and classification into six food groups were established for 4370 Korean food items. Based on food group information, daily servings of each food group per person were calculated using one-day $24 \mathrm{~h}$ recall data.

The serving of each food item was calculated as follows:

$\%$ RS $=\frac{\text { Daily servings consumed for each food group }}{\text { Recommended daily servings for each food group }} \times 100$.

\section{Other values}

In the present study, age (continuous), sex, living area, household type, household size (continuous), monthly household income (continuous) and education level were considered potential confounders. Household income was also presented as income quartile classified by using the equivalisation of income for persons within households to show household size and household income level as a single variable. The equivalised income has been used for OECD statistics recently to compare income inequality and poverty across countries, as well as KNHANES, which can be calculated by dividing monthly household income by the square root of the household size (e.g. a household of two adults and three children has an income of 50 000; the equivalised income for this household is 50000 divided by the square root of $5=22361)^{(27)}$. This equivalised income was then applied to each member of the household. In the categorical variables, living area had three categories: (i) rural areas; (ii) small cities; and (iii) metropolises. Household type also had three classes: (i) a person living alone or living with spouse or other siblings/relatives; (ii) a person/couple living with children or grandchildren; and (iii) a person/couple living with a spouse and children and grandchildren. The traditional family structure of South Korea was a three-generation extended family including grandparents, married son and daughter-in-law, and grandchildren. However, in the present day, this structure has changed into a nuclear family including parents and their children. One-generation families, such as those living alone or living with only a spouse, have also increased rapidly in South Korea. The change of household type would have an influence on family diet or the type of food consumed. Thus, this classification of household type is commonly included in national representative surveys and national statistics in South Korea. Education level had four categories: (i) completed elementary school or less; (ii) completed middle school; (iii) completed high school; or (iv) completed college or more. Also, experience with nutrition education was recorded as a dichotomous variable, with participants responding 'yes' or 'no' to the question, 'Have you received any nutrition education or counselling conducted in a health centre, local ward office, school, hospital, etc., during the past year?' Number of hours of sleep, coded as whole hours, was determined by asking 'How many hours do you sleep?' Subjective health status was assessed by asking the question, "What do you consider your usual state of health to be?'

\section{Statistical analyses}

Differences in the distribution of age group, sex, living area, household type, household income, education level and BMI were determined by weighted percentages using RaO-Scott $\chi^{2}$ tests. Significant differences in household size and monthly household income averages by food insufficiency group were identified using PROC SURVEYREG. The association of dietary intake and food group intake by sex with food insecurity was analysed using multiple linear regression. The $\beta$ coefficient and $P$ value, as well as the $P$ for trend, were calculated to estimate differences in food group intake by sex. Multiple logistic regression analysis was performed to estimate the association between eating/ health behaviours and food insecurity, and the $P$ for trend was also calculated. Age, sex, living area, household type, household size, monthly household income, education level and energy intake were controlled in all of the models. To account for the complex sampling design (i.e. stratified multistage sampling) of the KNHANES, all data analyses were performed using the PROC SURVEY procedure in the statistical software package SAS version 9.4. All tests of significance were two-tailed, and $P$ values $<0.05$ were considered statistically significant.

\section{Results}

General participant characteristics according to food insufficiency level are shown in Table 1. All of the participants were divided into three groups by food insufficiency level using the household questionnaire for household food insufficiency. All of the participants within a household were included because further analyses were based on individual data. Even though we used the food insufficiency data from the household questionnaire and divided all participants into groups, all further analyses were based on the individual data such as age, education, dietary habits and so on. All participants who satisfied our inclusion criterion within a selected household were included in this analysis.

The proportion of participants from the same household was as follows: $41.4 \%$ of households had one participant, $45.2 \%$ had two, $10.3 \%$ had three and $3.1 \%$ included four 
Table 1 General participant characteristics by food insufficiency level among Korean adults aged $\geq 19$ years from the Fifth Korea National Health and Nutrition Examination Survey (2010-2012)

\begin{tabular}{|c|c|c|c|c|}
\hline & \multicolumn{3}{|c|}{ Food insufficiency status } & \multirow[b]{2}{*}{$P$} \\
\hline & Food sufficient (\%) & Mildly food insufficient (\%) & Severely food insufficient (\%) & \\
\hline \multicolumn{5}{|l|}{ Age group (years) } \\
\hline $19-29$ & 20.7 & $18 \cdot 8$ & 12.5 & \multirow[t]{4}{*}{$<0.001$} \\
\hline $30-49$ & $45 \cdot 2$ & $41 \cdot 2$ & $30 \cdot 8$ & \\
\hline $50-64$ & $23 \cdot 3$ & $24 \cdot 6$ & $27 \cdot 9$ & \\
\hline$\geq 65$ & $10 \cdot 8$ & $15 \cdot 5$ & $28 \cdot 8$ & \\
\hline \multicolumn{5}{|l|}{ Sex } \\
\hline Men & $50 \cdot 4$ & 48.6 & 43.7 & \multirow{2}{*}{0.008} \\
\hline \multicolumn{4}{|l|}{ Living area } & \\
\hline Rural areas & $18 \cdot 2$ & $21 \cdot 2$ & $17 \cdot 1$ & \multirow[t]{3}{*}{0.028} \\
\hline Small cities & $33 \cdot 7$ & 31.4 & $40 \cdot 8$ & \\
\hline Metropolises & $48 \cdot 0$ & $47 \cdot 4$ & $42 \cdot 2$ & \\
\hline \multicolumn{5}{|l|}{ Household type $†$} \\
\hline One & $22 \cdot 0$ & $22 \cdot 4$ & $37 \cdot 7$ & \multirow[t]{3}{*}{$<0.001$} \\
\hline Two & $64 \cdot 3$ & $64 \cdot 0$ & $51 \cdot 7$ & \\
\hline Three & $13 \cdot 7$ & 13.5 & $10 \cdot 6$ & \\
\hline \multicolumn{5}{|l|}{ Education level } \\
\hline Elementary and less & $13 \cdot 3$ & $21 \cdot 0$ & $47 \cdot 0$ & \multirow[t]{4}{*}{$<0.001$} \\
\hline Middle school & 8.9 & 10.5 & $10 \cdot 9$ & \\
\hline High school & 38.6 & 39.5 & $32 \cdot 2$ & \\
\hline College or more & $39 \cdot 1$ & 28.9 & $9 \cdot 8$ & \\
\hline \multicolumn{5}{|l|}{ Weight status $\left(\mathrm{kg} / \mathrm{m}^{2}\right) \ddagger$} \\
\hline $\mathrm{BMl}<23$ & 44.7 & $46 \cdot 4$ & 41.0 & \multirow[t]{3}{*}{0.100} \\
\hline $23 \leq \mathrm{BMl}<25$ & 23.5 & $21 \cdot 7$ & 22.9 & \\
\hline $\mathrm{BMI} \geq 25$ & 31.8 & 31.9 & $36 \cdot 1$ & \\
\hline \multicolumn{5}{|l|}{ Income quartile§ } \\
\hline Q1 (lowest) & $18 \cdot 8$ & $30 \cdot 2$ & $62 \cdot 4$ & \multirow[t]{4}{*}{$<0.001$} \\
\hline Q2 & $24 \cdot 3$ & $27 \cdot 7$ & $20 \cdot 8$ & \\
\hline Q3 & $27 \cdot 1$ & 23.9 & $12 \cdot 4$ & \\
\hline Q4 (highest) & 29.9 & $18 \cdot 2$ & 4.5 & \\
\hline \multicolumn{5}{|c|}{ Household size (persons) } \\
\hline Mean & 3.42 & 3.32 & 2.69 & \multirow[t]{2}{*}{$<0.001$} \\
\hline SE & 0.03 & 0.03 & 0.09 & \\
\hline \multicolumn{5}{|c|}{ Household income (10000 Won per month) } \\
\hline Mean & 552.8 & $377 \cdot 2$ & $172 \cdot 5$ & \multirow[t]{2}{*}{$<0.001$} \\
\hline SE & $29 \cdot 8$ & $12 \cdot 3$ & 21.7 & \\
\hline
\end{tabular}

All \% are weighted percentages.

All analyses accounted for the complex sampling design effect and appropriate sampling weights of the national population-based survey.

tHousehold type has three classes: (i) a person living alone or living with a spouse or other siblings/relatives; (ii) a person/couple living with children or grandchildren; and (iii) a person/couple living with children or their spouse and grandchildren.

$\ddagger$ Weight status was categorised using the definition of the Korean Society for the Study of Obesity.

§Income quartile was based on the equivalised household income calculated by dividing monthly household income by the square root of the household size.

to six family members (data not shown). There were significant differences in average age $(P<0 \cdot 001)$, household size $(P<0.001)$ and monthly household income $(P<0 \cdot 001)$, as well as significant differences in distribution across age group $(P<0.001)$, sex $(P=0.008)$, living area $(P=0.028)$, household type $(P<0.001)$, education level $(P<0.001)$ and income quartile based on the equivalised household income accounted for the household size $(P<0.001)$, among food insufficiency status groups. The average age was $43.7,46.0$ and 52.6 years for the food-sufficient, mildly food-insufficient and severely food-insufficient group, respectively (data not shown). However, no significant difference in weight status by food insufficiency status was detected.

Table 2 describes the association between eating and health behaviours and food insufficiency after adjusting for age, sex, living area, household type, household size, monthly household income and education level.
When food insecurity was mild or severe, the occurrence of individuals skipping breakfast and receiving government food assistance was higher than in the food-sufficient group $\left(P_{\text {trend }}=0.001\right)$. The frequency of eating out $\left(P_{\text {trend }}<0.001\right)$, having family meals at breakfast or dinner $\left(P_{\text {trend }}=0.001\right)$, using nutritional labels when purchasing food $\left(P_{\text {trend }}=0.014\right)$ and drinking alcoholic beverages $\left(P_{\text {trend }}=0.012\right)$ was lower as food insufficiency level increased. Overall eating behaviours in the mildly and severely food-insufficient groups were poorer than those in the food-sufficient group, with the exception of eating out and drinking. These findings indicate that foodinsufficient individuals spend less money on eating out or drinking, as well as less time with their families. Food insufficiency was inversely associated with regular highintensity exercise $\left(P_{\text {trend }}=0.037\right)$ and amount of sleep $\left(P_{\text {trend }}=0.003\right)$; conversely, it was positively associated with poor subjective health status $\left(P_{\text {trend }}<0.001\right)$. The number of 
Table 2 Adjusted associations between eating and health behaviours and the level of food insufficiency among Korean adults aged $\geq 19$ years from the Fifth Korea National Health and Nutrition Examination Survey (2010-2012)

\begin{tabular}{|c|c|c|c|c|}
\hline & \multicolumn{3}{|c|}{ Food insufficiency status } & \multirow[b]{2}{*}{$P_{\text {trend }}$} \\
\hline & Food sufficient (\%) & Mildly food insufficient (\%) & Severely food insufficient (\%) & \\
\hline Skipping breakfast† & $20 \cdot 0$ & $22 \cdot 4$ & $29 \cdot 7$ & 0.001 \\
\hline \multicolumn{5}{|l|}{ Eating out } \\
\hline$\leq 3$ times/month & 24.6 & $32 \cdot 6$ & $51 \cdot 6$ & \multirow[t]{3}{*}{$<0.001$} \\
\hline$\overline{1}-4$ times/week & $32 \cdot 1$ & 28.5 & $25 \cdot 5$ & \\
\hline$\geq 5$ times/week & $43 \cdot 3$ & 38.9 & $23 \cdot 0$ & \\
\hline Family meal at breakfast & 53.7 & $49 \cdot 2$ & 39.7 & $<0.001$ \\
\hline Family meal at lunch & 23.5 & 24.7 & $28 \cdot 0$ & 0.461 \\
\hline Family meal at dinner & $66 \cdot 0$ & $62 \cdot 8$ & $54 \cdot 0$ & $<0.001$ \\
\hline Nutritional education experience & $4 \cdot 2$ & 3.4 & $1 \cdot 7$ & 0.006 \\
\hline Use of nutritional labels & $37 \cdot 7$ & 33.5 & $32 \cdot 1$ & 0.014 \\
\hline Food assistance programmes & $1 \cdot 1$ & $2 \cdot 1$ & 13.4 & $<0.001$ \\
\hline Current smokers & $24 \cdot 2$ & $25 \cdot 0$ & 24.9 & 0.075 \\
\hline \multicolumn{5}{|l|}{ Drinking alcohol during the past year } \\
\hline$<1$ drink/month & 33.3 & $37 \cdot 3$ & 43.9 & \multirow{3}{*}{0.012} \\
\hline 1-4 drinks/month & $40 \cdot 2$ & $38 \cdot 1$ & 33.9 & \\
\hline$\geq 2$ drinks/week & $26 \cdot \overline{5}$ & 24.6 & $22 \cdot 3$ & \\
\hline Vigorous physical activity§ & $16 \cdot 2$ & $13 \cdot 2$ & $13 \cdot 2$ & 0.037 \\
\hline \multicolumn{5}{|l|}{ Number of hours of sleep } \\
\hline$<6 \mathrm{~h} / \mathrm{d}$ & 11.9 & 13.6 & $24 \cdot 0$ & \multirow[t]{4}{*}{0.003} \\
\hline $6-7 \mathrm{~h} / \mathrm{d}$ & $25 \cdot 7$ & $27 \cdot 2$ & 24.5 & \\
\hline $7-8 \mathrm{~h} / \mathrm{d}$ & $30 \cdot 2$ & 28.2 & $22 \cdot 8$ & \\
\hline$\geq 8 \mathrm{~h} / \mathrm{d}$ & $32 \cdot 3$ & 31.0 & $28 \cdot 7$ & \\
\hline \multicolumn{5}{|l|}{ Subjective health status } \\
\hline Good & 38.7 & $32 \cdot 6$ & $20 \cdot 6$ & \multirow[t]{3}{*}{$<0.001$} \\
\hline Normal & $47 \cdot 8$ & 47.8 & 41.0 & \\
\hline $\mathrm{Bad}$ & 13.5 & $19 \cdot 6$ & 38.4 & \\
\hline
\end{tabular}

All \% are weighted percentages.

All analyses accounted for the complex sampling design effect and appropriate sampling weights of the national population-based survey.

All models were adjusted for age (continuous), sex, living area, household type, household size (continuous), monthly household income (continuous) and education level.

†The percentage of skipping breakfast in each group was adjusted for age (continuous), sex, living area, household type, household size (continuous), monthly household income (continuous) and education level.

¥Nutrition education experience is a dichotomous variable. Participants responded 'yes' or 'no' to the question, 'Have you received any nutrition education or counselling conducted in health centre, local ward office, school, hospital, etc., during the past year?'

$\S$ Vigorous physical activity was defined as high-intensity exercise of at least 20 min or more, at least three times per week.

participants sleeping $7 \mathrm{~h}$ or more was significantly lower in the severely food-insufficient group than in the foodsufficient group $\left(P_{\text {trend }}=0 \cdot 003\right)$.

Food insecurity status was also associated with dietary intake after adjusting for potential confounders (Table 3). Regarding macronutrients, protein intake, but not carbohydrate and fat intake or total energy intake, was lower in the mildly or severely food-insufficient group than in the food-sufficient group $\left(P_{\text {trend }}=0.001\right)$. However, the percentage of energy from macronutrients differed significantly among the food insufficiency status groups. While the percentage of energy from carbohydrates was positively related to the level of food insufficiency $\left(P_{\text {trend }}=0.005\right)$, the percentage from protein showed a negative relationship $\left(P_{\text {trend }}<0 \cdot 001\right)$. We found no association between food insufficiency and fat intake $\left(P_{\text {trend }}=0 \cdot 111\right)$. Micronutrient intakes of the mildly and severely food-insufficient groups were lower than those of the food-sufficient group after controlling for covariates. We found that micronutrient intakes tended to be low as food insufficiency was high $\left(P_{\text {trend }}<0 \cdot 05\right)$. The intakes of $\mathrm{Ca}\left(P_{\text {trend }}<0.001\right), \mathrm{Fe}\left(P_{\text {trend }}=0.004\right)$, vitamin A $\left(P_{\text {trend }}<0.001\right)$, thiamin $\left(P_{\text {trend }}=0.046\right)$, riboflavin $\left(P_{\text {trend }}=0.002\right)$, niacin $\left(P_{\text {trend }}<0.001\right)$ and vitamin C $\left(P_{\text {trend }}<0.001\right)$ were lowest in the severely food-insufficient group. We used percentage of recommended daily serving consumed for each of the six food groups (\%RS) to assess the dietary intake of each food group. Although grain consumption was positively associated $\left(P_{\text {trend }}<0.001\right)$ and vegetable consumption was negatively associated with the level of food insufficiency status $\left(P_{\text {trend }}<0 \cdot 001\right)$, both grain and vegetable consumption met the recommended daily serving among all participants, regardless of food insufficiency status. We also observed that individuals who were mildly or severely food-insufficient consumed less MFEB $\left(P_{\text {trend }}<0 \cdot 001\right)$ and fruits $\left(P_{\text {trend }}<0 \cdot 001\right)$. There was no linear trend between food insufficiency and consumption of milk/dairy products $\left(P_{\text {trend }}=0.430\right)$ and oils/sugars $\left(P_{\text {trend }}=0.319\right)$.

Table 4 summarises the association between food insufficiency and each food group by sex. For elucidation of the differences between them, the $\beta$ coefficient by multiple linear regression was used and can be interpreted as follows: when comparing the mildly or severely foodinsufficient group with the food-sufficient group, the 
Table 3 Adjusted associations between dietary intake and the level of food insufficiency among Korean adults aged $\geq 19$ years from the Fifth Korea National Health and Nutrition Examination Survey (2010-2012)

\begin{tabular}{|c|c|c|c|c|c|c|c|}
\hline \multirow[b]{3}{*}{ Dietary intake } & \multicolumn{6}{|c|}{ Food insufficiency status } & \multirow[b]{3}{*}{$P_{\text {trend }}$} \\
\hline & \multicolumn{2}{|c|}{ Food sufficient } & \multicolumn{2}{|c|}{ Mildly food insufficient } & \multicolumn{2}{|c|}{ Severely food insufficient } & \\
\hline & Mean & SE & Mean & SE & Mean & SE & \\
\hline \multicolumn{8}{|l|}{ Nutrients } \\
\hline Energy intake $(\mathrm{kJ} / \mathrm{d})$ & $8828 \cdot 3$ & $65 \cdot 7$ & $8644 \cdot 0$ & $68 \cdot 2$ & 7317.9 & $189 \cdot 7$ & 0.071 \\
\hline (\%EER) & 94.1 & 0.6 & 93.8 & 0.6 & 84.1 & 1.9 & 0.807 \\
\hline Carbohydrate (g/d) & $326 \cdot 8$ & $2 \cdot 3$ & $325 \cdot 0$ & $2 \cdot 3$ & $297 \cdot 5$ & 7.5 & 0.764 \\
\hline (\% of energy) & 65.4 & 0.2 & $67 \cdot 0$ & 0.2 & 71.4 & 0.7 & 0.005 \\
\hline Protein $(\mathrm{g} / \mathrm{d})$ & $78 \cdot 2$ & 0.8 & $74 \cdot 1$ & 0.8 & 57.4 & $1 \cdot 8$ & 0.001 \\
\hline (\% of energy) & $15 \cdot 2$ & 0.1 & 14.6 & 0.1 & $13 \cdot 6$ & 0.3 & $<0.001$ \\
\hline Fat $(g / d)$ & $46 \cdot 2$ & 0.6 & $43 \cdot 6$ & 0.6 & $30 \cdot 1$ & 1.7 & 0.635 \\
\hline (\% of energy) & $19 \cdot 4$ & 0.2 & 18.4 & 0.2 & 14.9 & 0.6 & 0.111 \\
\hline $\mathrm{Ca}(\mathrm{mg} / \mathrm{d})$ & $542 \cdot 7$ & $6 \cdot 2$ & $511 \cdot 2$ & $5 \cdot 2$ & $396 \cdot 2$ & $17 \cdot 9$ & $<0.001$ \\
\hline $\mathrm{Fe}(\mathrm{mg} / \mathrm{d})$ & $16 \cdot 0$ & 0.2 & $15 \cdot 3$ & 0.2 & 11.9 & 0.5 & 0.004 \\
\hline Vitamin A (RE/d) & 935.9 & $24 \cdot 6$ & 853.3 & $19 \cdot 2$ & $500 \cdot 1$ & $24 \cdot 0$ & $<0.001$ \\
\hline Thiamin $(\mathrm{mg} / \mathrm{d})$ & 1.44 & 0.02 & 1.39 & 0.01 & 1.07 & 0.04 & 0.046 \\
\hline Riboflavin (mg/d) & 1.34 & 0.01 & 1.27 & 0.01 & 0.94 & 0.03 & 0.002 \\
\hline Niacin $(\mathrm{mg} / \mathrm{d})$ & $18 \cdot 6$ & 0.2 & 17.5 & 0.2 & $13 \cdot 4$ & 0.4 & $<0.001$ \\
\hline Vitamin C (mg/d) & 119.5 & 1.8 & $106 \cdot 3$ & 1.8 & 71.5 & $3 \cdot 3$ & $<0.001$ \\
\hline \multicolumn{8}{|l|}{ Food group intakes (\%RS) } \\
\hline Grains & 92.5 & 0.7 & $95 \cdot 2$ & 0.7 & $95 \cdot 8$ & $2 \cdot 5$ & $<0.001$ \\
\hline MFEB & $99 \cdot 3$ & $1 \cdot 3$ & $92 \cdot 0$ & $1 \cdot 3$ & $68 \cdot 1$ & 3.3 & $<0.001$ \\
\hline Vegetables & $127 \cdot 7$ & 1.6 & 121.9 & 1.5 & $99 \cdot 2$ & $4 \cdot 2$ & $<0.001$ \\
\hline Fruits & $91 \cdot 0$ & $2 \cdot 9$ & 81.5 & $2 \cdot 9$ & $49 \cdot 2$ & $5 \cdot 4$ & $<0.001$ \\
\hline Milk and dairy products & 53.3 & 1.7 & $49 \cdot 4$ & 1.6 & 33.4 & 4.6 & 0.430 \\
\hline Oils and sugars & $139 \cdot 2$ & $2 \cdot 3$ & $132 \cdot 9$ & $2 \cdot 2$ & $104 \cdot 7$ & 8.6 & 0.319 \\
\hline
\end{tabular}

\%EER, percentage of total daily energy intake relative to the estimated energy requirement; RE, retinol equivalents; \%RS, percentage of recommended daily serving consumed for each of the six food groups; MFEB, meat, fish, eggs, and beans.

All analyses accounted for the complex sampling design effect and appropriate sampling weights of the national population-based survey.

All models were adjusted for age (continuous), sex, living area, household type, household size (continuous), monthly household income (continuous), education level and total energy intake (continuous).

Table 4 Regression coefficients of food insecurity for intake of each food group among Korean adults aged $\geq 19$ years from the Fifth Korea National Health and Nutrition Examination Survey (2010-2012)

\begin{tabular}{|c|c|c|c|c|c|c|}
\hline \multirow[b]{3}{*}{ Sex } & \multirow[b]{3}{*}{ Food group (\%RS) } & \multirow[b]{3}{*}{ Food sufficient } & \multicolumn{4}{|c|}{ Food insufficiency status } \\
\hline & & & \multicolumn{2}{|c|}{ Mildly food insufficient } & \multicolumn{2}{|c|}{ Severely food insufficient } \\
\hline & & & $\beta$ & SE & $\beta$ & $\mathrm{SE}$ \\
\hline \multirow[t]{6}{*}{ Total† } & Grains & Ref. & 1.8 & $0.8^{*}$ & 6.5 & $2 \cdot 0^{\star *}$ \\
\hline & MFEB & Ref. & $-4 \cdot 0$ & $1.5^{\star \star}$ & -9.5 & $3 \cdot 1^{\star \star}$ \\
\hline & Vegetables & Ref. & -5.7 & $2 \cdot 0^{\star *}$ & $-18 \cdot 8$ & $4 \cdot 4^{\star \star *}$ \\
\hline & Fruits & Ref. & $-10 \cdot 3$ & $2 \cdot 9^{\star \star \star}$ & $-40 \cdot 2$ & $7 \cdot 0^{\star \star \star}$ \\
\hline & Milk and dairy products & Ref. & -0.5 & $2 \cdot 1$ & $-6 \cdot 8$ & 4.7 \\
\hline & Oils and sugars & Ref. & $1 \cdot 8$ & 2.5 & $6 \cdot 1$ & 6.9 \\
\hline \multirow[t]{6}{*}{ Men‡ } & Grains & Ref. & 1.7 & $1 \cdot 1$ & $7 \cdot 6$ & $3 \cdot 7^{\star}$ \\
\hline & MFEB & Ref. & -3.5 & $2 \cdot 2$ & $-17 \cdot 2$ & $5 \cdot 0^{\star \star *}$ \\
\hline & Vegetables & Ref. & $-5 \cdot 0$ & 2.9 & $-27 \cdot 3$ & $7 \cdot 0^{\star \star \star}$ \\
\hline & Fruits & Ref. & -7.4 & $3 \cdot 5^{\star}$ & $-31 \cdot 7$ & $7 \cdot 9^{\star \star \star}$ \\
\hline & Milk and dairy products & Ref. & 3.9 & $3 \cdot 1$ & -1.1 & 8.0 \\
\hline & Oils and sugars & Ref. & $2 \cdot 4$ & 3.5 & $12 \cdot 1$ & $12 \cdot 5$ \\
\hline \multirow[t]{6}{*}{ Women } & Grains & Ref. & $2 \cdot 6$ & $0.8^{* *}$ & 6.7 & $2 \cdot 1^{\star *}$ \\
\hline & MFEB & Ref. & -4.4 & $1 \cdot 6^{\star \star}$ & $-3 \cdot 2$ & 3.7 \\
\hline & Vegetables & Ref. & $-6 \cdot 0$ & $2 \cdot 2^{\star \star}$ & $-10 \cdot 7$ & $4.9^{*}$ \\
\hline & Fruits & Ref. & -11.5 & $4 \cdot 2^{\star \star}$ & $-46 \cdot 0$ & $9 \cdot 5^{\star \star \star}$ \\
\hline & Milk and dairy products & Ref. & $-4 \cdot 3$ & $2 \cdot 3$ & -11.4 & $4 \cdot 7^{\star}$ \\
\hline & Oils and sugars & Ref. & $2 \cdot 1$ & 3.0 & $2 \cdot 3$ & $7 \cdot 4$ \\
\hline
\end{tabular}

$\beta, \beta$ coefficient; \%RS, percentage of recommended daily serving consumed for each of the six food groups; MFEB, meat, fish, eggs and beans; Ref., reference category. All analyses accounted for the complex sampling design effect and appropriate sampling weights of the national population-based survey.

${ }^{\star} P<0.05,{ }^{\star \star} P<0.01,{ }^{\star \star \star} P<0.001$.

†Model was adjusted for age (continuous), sex, living area, household type, household size (continuous), monthly household income (continuous), education level and total energy intake (continuous).

¥Model was adjusted for age (continuous), living area, household type, household size (continuous), monthly household income (continuous), education level and total energy intake (continuous). 
difference in grain consumption by food insufficiency level $(\beta$ coefficient $=1.8$ in the mildly food-insufficient group and 6.5 in the severely food-insufficient group) was higher in the food-sufficient group $v$. the severely foodinsufficient group than in the food-sufficient group $v$. the mildly food-insufficient group. It showed that the grain intake of the mildly food-insufficient group was $1.8 \%$ higher in the percentage of recommended daily serving consumed compared with that in the food-sufficient group, and the grain intake of the severely foodinsufficient group was $6.5 \%$ higher in the percentage of recommended daily serving consumed than that in the food-sufficient group.

Four food groups (grains, MFEB, vegetables and fruits) were associated with food insufficiency status. When we compared the food-sufficient group with the mildly foodinsufficient group or severely food-insufficient group, the food-sufficient group's grain consumption was lower that of the other groups, while the food-sufficient group's consumption of MFEB, vegetables and fruits was higher than that of the other groups. In men, there were no significant food group differences between the foodsufficient group and the mildly food-insufficient group, with the exception of fruits, while significant differences were observed between the food-sufficient and the severely food-insufficient groups. Compared with the food-sufficient group, grain consumption of the severely food-insufficient group was significantly higher $(P<0 \cdot 01)$, while MFEB, vegetable and fruit consumption were markedly lower $(P<0 \cdot 01)$. In particular, fruit consumption was significantly lower in both the mildly and severely food-insufficient groups than in the food-sufficient group $(P<0.001)$; moreover, the difference between the foodsufficient group and the severely food-insufficient group was greater than that between the food-sufficient group and the mildly food-insufficient group. In women, unlike men, significant differences were observed between the food-sufficient and mildly food-insufficient groups in grain, MFEB, vegetable and fruit intakes $(P<0 \cdot 01)$. Grain consumption was higher $(P<0 \cdot 01)$, whereas MFEB $(P<0.01)$, vegetable $(P<0.01)$ and fruit $(P<0.01)$ consumption were lower according to the level of food insufficiency when comparing the food-sufficient group with the mildly food-insufficient group. We found the same trend in grain, vegetable, fruit and milk/dairy product intakes $(P<0.05)$, but not in MFEB, between the food-sufficient group and the severely food-insufficient group. Fruit consumption by women was markedly lower in the severely food-insufficient group compared with the food-sufficient group $(P<0 \cdot 001)$. The difference in fruit consumption between the food-sufficient and the severely food-insufficient groups was considerably greater in women than in men ( $\beta$ coefficient $=-31.7$ in men $v$. $-46 \cdot 0$ in women). This also means that the fruit intake of men in the severely food-insufficient group was $31.7 \%$ lower in the percentage of recommended daily serving consumed compared with that in the food-sufficient group, and the fruit intake of women in the severely food-insufficient group was $46 \%$ lower in the percentage of recommended daily serving consumed than that in food-sufficient group. Low milk/dairy product intake by food insufficiency was observed only in women $(P<0 \cdot 05)$.

\section{Discussion}

In the present study, which used a national sample of the Korean adult population, macronutrient as well as micronutrient intakes differed significantly according to the level of food insufficiency after adjusting for all potential confounding factors. Eating and health behaviours also differed significantly according to the level of food insufficiency. As expected, nutrient intake was associated with the food insufficiency level. Interestingly, high carbohydrate intake and low protein intake were associated with food insufficiency. We found no association between food insufficiency and fat intake. Compared with Western population studies ${ }^{(10,28-32)}$, where it has been reported that people who experience food insecurity or low income are likely to consume foods that are high in fat or simple sugars because of limited resources, our study showed no association between food insufficiency and oil/sugar intake or fat intake. A possible explanation is that steamed rice is a Korean staple food; thus, people in the mildly and severely food-insufficient groups may obtain energy primarily from carbohydrate, not protein or fat intake. Kim et al. ${ }^{(33)}$ also suggested that the low fat and high carbohydrate intakes in South Koreans, despite the increase in gross domestic product, may be due to cooking methods and movements to retain the traditional diet.

Along with macronutrient intakes, the intakes of almost all micronutrients, including $\mathrm{Ca}, \mathrm{Fe}$, vitamin $\mathrm{A}$, thiamin, riboflavin, niacin and vitamin $\mathrm{C}$, were significantly lower in the food-insufficient groups. Several studies ${ }^{(6,11)}$ have evaluated micronutrient intakes and food insecurity/ insufficiency. In the US adult population, data from NHANES 1988-1994 showed that food-insufficient families had lower $\mathrm{Ca}, \mathrm{Fe}$ and $\mathrm{Mg}$ intakes than did those with sufficient food ${ }^{(11)}$.

We found that the consumption of MFEB, vegetables and fruits was low markedly according to the level of food insufficiency. Our findings were in accordance with prior studies $^{(2,5,19)}$. According to Lyu et al. ${ }^{(19)}$, low-income families in Taiwan had more frequent food security concerns and reported less fish and fruit in their daily meals than did middle-income families. However, at $99.2 \%$, vegetable consumption was close to the recommended daily serving even in the severely food-insufficient group in the present study. As a typical Korean meal consists of rice and side dishes, including kimchi, which contains abundant vegetables, vegetable consumption is not a serious concern. In Korea, grain is generally one of the 
cheapest sources of energy. Animal foods such as meat and fish are relatively expensive; however, eggs and legumes are less expensive than other protein sources. Shim et $a l^{(34)}$ investigated the healthy diet and food cost among South Korean adults and reported the food intake of the meat/fish/beans/eggs category was most costsensitive. Vegetable prices are not expensive, but lowincome groups or the elderly have a high level of dependence on kimchi but not fresh vegetables. The price of fruits and dairy products is also expensive. In the case of dairy products, the low consumption can be caused by Koreans' eating habits as well as the price.

When we examined the factors related to consumption of each food group, the level of food insufficiency remained meaningful after adjusting for all sociodemographic factors. Furthermore, its associations differed by sex. In women, unlike men, the difference in food consumption between the food-sufficient and both the mildly and severely food-insufficient groups was also remarkable in the current study. These findings suggested that women's overall dietary intake was negatively associated with the level of food insufficiency and dietary intake in women would be more sensitive to food insufficiency than that in men. The poorer intake among women is often attributed to their feeding their children prior to feeding themselves in Western countries ${ }^{(6,12)}$. Tarasuk and colleagues ${ }^{(6)}$ reported that the dietary intake of low-income and predominantly food-insecure women with children in Canada was significantly decreased, particularly in energy intake, milk products and vegetables. This was likely due to depletion of household resources, such as household income; women who were moderately or severely food insufficient exhibited significantly reduced consumption of energy, carbohydrate, vitamin $\mathrm{B}_{6}$, and fruit and vegetables. Similarly, Rose ${ }^{(12)}$ reviewed then recent research performed in the USA and reported that the risk of decreased nutrient intake was higher among adult women, as well as elderly individuals, in foodinsufficient households. This implies that women are more likely to cut back on food spending to make room for other essentials. Unfortunately, studies investigating women's susceptibility to food insecurity directly have not been conducted in South Korea yet. Our study, indicating that women's dietary intake possibly is more sensitive to food insecurity than men's, suggests that women's susceptibility to food insecurity may be an important area worth further research.

In men, however, the difference in food consumption between the food-sufficient and severely food-insufficient groups was more noticeable than that between the food-sufficient and mildly food-insufficient groups. The discrepancy in intake of all food groups, except fruits, between the severely food-insufficient and the foodsufficient groups was also greater in men than in women. These findings suggest that, compared with the dietary intake of the food-sufficient group, men in the severely food-insufficient group experience more serious food insufficiency than women.

With regard to eating and health behaviour by food insufficiency level, we found that a greater number of participants reported poorer health status, less physical activity and less time spent sleeping according to food insufficiency level. These findings are in accordance with previous studies ${ }^{(2,7,13,17)}$, which found that food insufficiency or food insecurity was associated with poor general health, increased health-care utilisation and depression. Ding et $a l^{(17)}$ reported an association between food insecurity and poor sleep in US adults. Those authors showed that women who were very low in food security reported approximately $30 \mathrm{~min}$ less sleep per day compared with those who experienced food security. Seligman et $a{ }^{(7)}$ reported an inverse relationship between food insecurity and chronic diseases, such as heart disease, hypertension and hyperlipidaemia. This implies that food insecurity is associated with undesirable health behaviours that lead to chronic disease.

It was interesting that compared with the food-sufficient group, a greater number of participants in the foodinsufficient groups participated in food assistance programmes, but fewer received nutritional education in the present study. Recently, Lyles and colleagues ${ }^{(14)}$ reported that food-insecure individuals showed significantly greater improvement in $\mathrm{Hb}_{1 \mathrm{C}}$, self-efficacy, as well as increased fruit and vegetable consumption compared with foodsecure individuals over 1 year of intervention, even though the intervention did not specifically address improving food insecurity. This implies that specific nutritional education targeting food insufficiency/food insecurity would prompt food-insufficient/food-insecure individuals to improve their eating behaviours and dietary quality.

There were several limitations to the current study. Since KNHANES is a cross-sectional study with one $24 \mathrm{~h}$ recall, we could not determine causal relationships between food insufficiency and unhealthy eating/health behaviours and dietary intake. Household food insufficiency was used as an indicator of household food insecurity since household food insecurity status of KNHANES was measured and reported by a single question asking household food insufficiency from 2005 to 2011. Using a single item to measure food insufficiency could underestimate the prevalence due to its low sensitivity ${ }^{(15,16)}$. Recently, a study ${ }^{(24)}$ performed in South Korea validated newly developed food security measures based on the US Household Food Security Survey Module, and assessed the sensitivity and specificity of KNHANES's foodinsufficiency questionnaire for assessing food security status using the newly developed food security measures. The sensitivity and specificity of the food insufficiency questionnaire were $56.8 \%$ and $92.3 \%$, respectively. This is consistent with the results of studies by Nolan et al. ${ }^{(15)}$ and Keenan et $a l .{ }^{(16)}$. On the other hand, Urke et al. ${ }^{(35)}$ reported the validity of a single item measuring food 
security, showing that it could be useful in a large-scale sample in terms of both rapid assessment and feasibility.

Nevertheless, to our knowledge, the present study was the first comprehensive one to examine the association between dietary intake and food insecurity in an Asian population.

\section{Conclusions}

In the present study, dietary intake as well as eating and health behaviours were found to be adversely associated with food insufficiency. Our findings suggest that targeted support is necessary to help food-insufficient individuals improve their dietary quality and health status.

\section{Acknowledgements}

Financial support: This work was carried out with the support of the 'Research Program for Agricultural Science and Technology Development', National Academy of Agricultural Science, Rural Development Administration, Republic of Korea (project number PJ00899503). The funder had no role in the design, analysis or writing of this article. Conflict of interest: None. Authorship: S.E.L., Y.S. and H.-Y.P. contributed to the interpretation of the data; S.E.L. wrote the manuscript; Y.S., H.-Y.P., Y.K. and J.C. were involved in critical revision of the manuscript for important intellectual content; and H.-Y.P. had primary responsibility for the final content. All authors read and approved the final manuscript. Ethics of human subject participation: The KNHANES was approved by the Institutional Review Board of the Korea CDC (IRB numbers 2010-02CON-21-C, 2011-02CON-06-C and 2012-01EXP-01-2C).

\section{References}

1. Carlson SJ, Andrews MS \& Bickel GW (1999) Measuring food insecurity and hunger in the United States: development of a national benchmark measure and prevalence estimates. J Nutr 129, 2S Suppl., 510S-516S.

2. Vozoris NT \& Tarasuk VS (2003) Household food insufficiency is associated with poorer health. J Nutr 133, 120-126.

3. Tarasuk VS (2001) Household food insecurity with hunger is associated with women's food intakes, health and household circumstances. J Nutr 131, 2670-2676.

4. Coleman-Jensen A, Andrews M \& Carlson S (2012) Household food security in the United States in 2011. Economic Research Report no. ERR-141. http://www.ers.usda.gov/ publications/err-economic-research-report/err141/reportsummary.aspx (assessed June 2015).

5. Hanson KL \& Connor LM (2014) Food insecurity and dietary quality in US adults and children: a systematic review. Am J Clin Nutr 100, 684-692.

6. Tarasuk V, McIntyre L \& Li J (2007) Low-income women's dietary intakes are sensitive to the depletion of household resources in one month. J Nutr 137, 1980-1987.
7. Seligman HK, Laraia BA \& Kushel MB (2010) Food insecurity is associated with chronic disease among low-income NHANES participants. J Nutr 140, 304-310.

8. Briefel RR \& Woteki CE (1992) Development of food sufficiency questions for the third National Health and Nutrition Examination Survey. J Nutr Educ 24, Suppl. 1, 24S-28S.

9. Rose D \& Oliveira V (1997) Nutrient intakes of individuals from food-insufficient households in the United States. Am J Public Health 87, 1956-1961.

10. Mello JA, Gans KM, Risica PM et al. (2010) How is food insecurity associated with dietary behaviors? An analysis with low-income, ethnically diverse participants in a nutrition intervention study. J Am Diet Assoc 110, 1906-1911.

11. Dixon LB, Winkleby MA \& Radimer KL (2001) Dietary intakes and serum nutrients differ between adults from food-insufficient and food-sufficient families: Third National Health and Nutrition Examination Survey, 1988-1994. J Nutr 131, 1232-1246.

12. Rose D (1999) Economic determinants and dietary consequences of food insecurity in the United States. $J$ Nutr 129, 2S Suppl., 517S-520S.

13. Ramsey R, Giskes K, Turrell G et al. (2012) Food insecurity among adults residing in disadvantaged urban areas: potential health and dietary consequences. Public Health Nutr 15, 227-237.

14. Lyles CR, Wolf MS, Schillinger D et al. (2013) Food insecurity in relation to changes in hemoglobin A1c, selfefficacy, and fruit/vegetable intake during a diabetes educational intervention. Diabetes Care 36, 1448-1453.

15. Nolan M, Rikard-Bell G, Mohsin M et al. (2006) Food insecurity in three socially disadvantaged localities in Sydney, Australia. Health Promot J Aust 17, 247-254.

16. Keenan DP, Olson C, Hersey JC et al. (2001) Measures of food insecurity/security. J Nutr Educ 33, Suppl. 1, S49-S58.

17. Ding M, Keiley MK, Garza KB et al. (2015) Food insecurity is associated with poor sleep outcomes among US adults. J Nutr 145, 615-621.

18. International Monetary Fund (2014) World economic outlook database October 2014. http://www.imf.org/external/ pubs/ft/weo/2014/02/weodata/index.aspx (accessed February 2015).

19. Lyu LC, Yu YP, Lee JS et al. (2006) Food and nutrient intakes for families in Taipei, Taiwan. J Food Compost Anal 19, S22-S30.

20. Lo YT, Chang YH, Lee MS et al. (2012) Dietary diversity and food expenditure as indicators of food security in older Taiwanese. Appetite 58, 180-187.

21. Oh SY \& Hong MJ (2003) Food insecurity is associated with dietary intake and body size of Korean children from low-income families in urban areas. Eur J Clin Nutr $\mathbf{5 7}$, 1598-1604.

22. Korea Centers for Disease Control and Prevention (2013) The Fifth Korea National Health and Nutrition Examination Survey (KNHANES V). Cheongwon: Korea CDC.

23. Kim Y (2014) The Korea National Health and Nutrition Examination Survey (KNHANES): current status and challenges. Epidemiol Health 36, e2014002.

24. Kim K, Hong SA, Kwon SO et al. (2011) Validation of food security measures for the Korean National Health and Nutrition Examination Survey. Korean J Community Nutr 16, 771-781.

25. Korean Nutrition Society (2010) Dietary Reference Intakes for Koreans, 1st revision. Seoul: KNS.

26. Song S, Jung HJ, Shim JE et al. (2014) Assessment of food group intake in Korean population with a newly-developed food group database. J Food Compost Anal 36, 72-78.

27. Organisation for Economic Co-operation and Development (2014) Health Statistics 2014: Definitions, Sources and Methods - Perceived health status by socio-economic status. 
http://www.oecd.org/els/health-systems/Table-of-ContentMetadata-OECD-Health-Statistics-2014.pdf (accessed May 2015).

28. Drewnowski A (2004) Obesity and the food environment: dietary energy density and diet costs. Am J Prev Med 27, 154-162.

29. Drewnowski A \& Specter S (2004) Poverty and obesity: the role of energy density and energy costs. Am J Clin Nutr 79, 6-16.

30. Wilde PE, McNamara PE \& Ranney CK (2000) The Effect on Dietary Quality of Participation in the Food Stamp and WIC Programs. Food Assistance and Nutrition Research Report no. FANRR-9. Washington, DC: US Department of Agriculture, Economic Research Service.
31. Darmon N \& Drewnowski A (2008) Does social class predict diet quality? Am J Clin Nutr 87, 1107-1117.

32. Townsend MS, Aaron GJ, Monsivais P et al. (2009) Less-energy-dense diets of low-income women in California are associated with higher energy-adjusted diet costs. Am J Clin Nutr 89, 1220-1226.

33. Kim S, Moon S \& Popkin BM (2000) The nutrition transition in South Korea. Am J Clin Nutr 71, 44-53.

34. Shim JE, Jung H \& Paik HY (2006) Effects of food cost on a diet quality. J Nutr Health 39, 832-840.

35. Urke HB, Cao ZR \& Egeland GM (2014) Validity of a single item food security questionnaire in Arctic Canada. Pediatrics 133, e1616-e1623. 